\title{
A concepção e formato do programa atitude
}

\author{
Design and format of attitude program
}

\begin{abstract}
Resumo:
O Programa Atitude foi uma proposta de intervenção social promovido pelo governo do Estado do Paraná com objetivo de atuar junto aos municípios que apresentavam situação de vulnerabilidade social e violação dos direitos de crianças e adolescentes. O Programa priorizou a formação de Redes de Proteção locais que incluíssem ações, programas e projetos de caráter público ou privado, de modo a atender a população, principalmente com fragilidade de vínculos familiares; uso de drogas; evasão escolar; baixa oferta de atividades lúdicas, esportivas, artísticas e culturais; carência de práticas de convivência comunitária. O Programa contou com o financiamento do Fundo Estadual da Infância e Adolescência (FIA), com aprovação do Conselho Estadual dos Direitos da Criança e do Adolescente do Paraná (CEDCAPR), realizado durante os anos de 2008 a 2011 sob a gestão compartilhada entre Estado e municípios. A execução do Programa privilegiou o trabalho por meio de equipes interdisciplinares (184 técnicos das áreas de Psicologia, Serviço Social, Educação Física, Artes e Ciências Sociais) e estagiários distribuídos nos 34 núcleos do Programa para realização de diagnóstico local, a articulação da rede e as ações de execução direta com as crianças, adolescentes e suas famílias.
\end{abstract}

Aline Pedrosa Fioravante*

Palavras-Chave: Crianças e adolescente. Direitos sociais. Proteção social.

\begin{abstract}
:
The Attitude program was a social proposal to intervention promoted by the government of the State of Paraná in order to work with the municipalities that had social vulnerability and violation of the rights of children and adolescents. The program prioritized the training of local protection networks that include actions, programs and projects for both public and private, in order to serve the population, especially with the fragility of family ties, drug use, truancy, low supply of recreational activities, sporting, artistic and cultural practices, lack of community life. The program included funding from the State Fund for Childhood and Adolescence (FIA), with approval of the State Council of Child and Adolescent Parana (PR-CEDCA), performed during the years 2008 to 2011 under the shared management between State and municipalities. Running the Program privileged to work through interdisciplinary teams (184 technicians in the areas of Psychology, Social Work, Physical Education, Arts and Social Sciences) and distributed in the 34 trainees Program cores to perform local diagnosis, the joint network and enforcement actions directly with children, adolescents and the families.
\end{abstract}

\footnotetext{
* Psicóloga e Bacharel em Direito. Texto escrito a partir da experiência como Coordenadora Estadual do Programa Atitude - 2008 a 2011. alineeari@gmail.com
} 
Keywords: Children and adolescents. Social rights. Social protection.

\section{Introdução}

O Programa Atitude foi uma experiência de intervenção social e comunitária para a promoção e garantia de direitos de crianças e adolescentes desenvolvidas em alguns territórios paranaenses durante os anos de 2008 a 2011, sob a gestão compartilhada entre Estado e municípios. Foi discutido e concebido no âmbito do Conselho Estadual dos Direitos da Criança e do Adolescente do Paraná (CEDCA-PR) - Deliberação 019/2007, como uma proposta para promover ações integradas e concentradas em territórios, atuando sobre os fatores de risco de exposição de crianças e jovens a situações de violência, tais como: fragilidade de vínculos familiares; uso abusivo de drogas; evasão escolar; baixa oferta de atividades lúdicas, esportivas, artísticas e culturais; carência de práticas de convivência comunitária; opções restritas de profissionalização, de maneira a proteger as crianças, reduzir os índices de violência e criar oportunidades aos jovens.

O contexto de sua concepção e planejamento no CEDCA-PR envolveu uma reflexão sobre a finalidade e destinação do Fundo Estadual da Infância e Adolescência (FIA), considerando sua importância para o fortalecimento do Sistema de Garantia de Diretos. Neste sentido, houve, à época, uma tendência a se evitar a dispersão de recursos em financiamentos de projetos governamentais e não governamental de pouco impacto e nem sempre, tecnicamente, condizentes ao formato da política de atendimento à criança e ao adolescente.

Dessa reflexão, algumas ideias foram fortalecendo a base para a aprovação do Programa Atitude. De modo simplificado, elas podem ser apontadas como: a) a consideração das situações de violação de direitos, hierarquizando aquelas de maior exposição ao risco e menor possibilidade da criança e do adolescente serem protegidos, para aquela de menor risco e maiores condições de proteção; b) o respeito a dados e informações da situação da infância e adolescência em âmbito estadual, priorizando temáticas mais significativas, assim como regiões, municípios e localidades com maior concentração dos problemas; c) a priorização da formação de Redes de Proteção locais que incluíssem ações, programas e projetos de forma intersetorial e pública, sejam com 
execução governamental ou não governamental; d) o apoio, de forma complementar e transversal, às políticas básicas de promoção de direitos, com a priorização da destinação dos recursos ao atendimento direto e especializado às crianças, adolescentes e suas famílias; e) a inclusão de ações de qualificação dos atores integrantes do Sistema de Garantia de Direitos da Criança e do Adolescente.

Assumindo tais pressupostos, o Programa Atitude foi apresentado pela então Secretaria da Criança e da Juventude (SECJ) ao CEDCA-PR como uma ação que envolvia outras Secretarias de Estado, parcerias com 10 (dez) municípios e Instituições de Ensino Superior, sendo aprovado em dezembro de 2007.

Com base em critérios conjugados para a análise da realidade de crianças e adolescentes no Estado do Paraná, ${ }^{1}$ foram estabelecidos os municípios e territórios a integrarem o Programa Atitude, assim como seus eixos de execução e seu formato de gestão.

Os municípios selecionados foram Almirante Tamandaré, Cascavel, Colombo, Foz do Iguaçu, Cambé, Londrina, Sarandi, Ponta Grossa, Piraquara, São José dos Pinhais, sendo esses elegidos pelos próprios municípios 34 (trinta e quatro) territórios de atuação, de acordo com suas dimensões populacionais.

Sua proposta justificou-se como uma intervenção multidimensionada e concentrada sobre os impactos das violações de direitos contra o público infantojuvenil em territórios de alto risco com ações estruturadas em eixos de ação que objetivaram:

\footnotetext{
${ }^{1}$ Os critérios utilizados para a priorização dos territórios e municípios a integrarem o Programa Atitude, de acordo com a Deliberação 019/2007 do CEDCA, foram:

- população total acima de 70.000 habitantes - concentração populacional (IBGE, 2007);

- receita per capita abaixo de $\mathrm{R} \$ 1.100,00$ (mil e cem reais) - (SECRETARIA DO TESOURO NACIONAL, 2007);

- localização em áreas metropolitanas ou conurbadas;

- incidência de alto índice de violência juvenil, considerando os seguintes indicadores: a) número de apreensões de adolescentes em delegacias acima de 115 (Grupo de Apoio e Planejamento/SESP, 2006); b) registros de procedência dos adolescentes internados em Unidades Socioeducativas superior a 20 (Secretaria de Estado da Criança e da Juventude - SECJ, 2006); c) perfil do adolescente em conflito com a lei com relação ao uso e ao tráfico de drogas (Fonte: Relatórios Estatísticos da Secretaria de Estado da Criança e do Adolescente - SECJ, 2005/2006);

- alta incidência de indicadores de violência praticada contra crianças e adolescentes, considerando os seguintes indicadores: a) número de homicídios de crianças e de adolescentes entre 1 e 19 anos acima de 10 (Sistema de informações do SUS, MINISTÉRIO DA SAÚDE, 2001 a 2005); b) número de registros de violência física, psicológica e sexual superior a 25 (Sistema de Informação para a Infância e a Adolescência - SIPIA, Secretaria de Estado da Criança e da Juventude - SECJ, 2006).

- expressão de contraste econômico-social em um espaço territorial comum e próximo, intensificando os indicadores de violência urbana (IPARDES, Os vários Paranás, 2005).
} 
- o fortalecimento dos vínculos familiares e comunitários;

- a identificação e o atendimento de casos de crianças e adolescentes vítimas e autores de violências;

- a proposição de práticas formativas, socializadoras e de cidadania, por meio de oficinas de cultura, esporte, lazer e qualificação profissional;

- o desenvolvimento de abordagens educativas e terapêuticas aos adolescentes usuários de álcool e outras drogas;

- a participação social da juventude e o fortalecimento e articulação das estruturas locais do Sistema de Garantia dos Direitos das Crianças e Adolescentes.

Por meio de um formato de gestão compartilhada, Estado e Municípios dividiram responsabilidades. O Estado executou diretamente as ações que envolviam a existência dos recursos humanos para a implantação dos núcleos do Programa e o pagamento do auxíliofinanceiro aos bolsistas-atitude, jovens da comunidade que assumiam papéis de agentes de cidadania vinculados aos núcleos. E os municípios, a partir do repasse financeiro realizado pelo CEDCA-PR, assumiram a implementação da infraestrutura física e material de todo o Programa, além do fortalecimento de toda a rede de serviços necessária para o atendimento das demandas de violações de direitos a serem identificadas, como por exemplo, a implantação de CAPSs (Centros de Atenção Psicossocial) infantojuvenil, CREAS (Centros de Referência Especializados em Assistência Social), espaços comunitários para esporte e lazer etc.

Foram concebidas estruturas colegiadas que atuaram no apoio à gestão do Programa. No âmbito estadual, o Comitê Gestor Estadual congregou todas as Secretarias de Estado envolvidas na execução direta ou indireta (Secretaria de Saúde, de Educação, de Segurança, de Ciência e Tecnologia, do Trabalho, Emprego e Promoção Social e Secretaria de Planejamento). No âmbito municipal, foi constituído o Comitê Gestor Municipal, que, de modo similar, reuniu todas as secretarias municipais, demais órgãos e instituições envolvidas nas ações do Programa Atitude e, no âmbito comunitário, foram formados grupos de apoio locais com representantes da Rede de Proteção e integrantes das comunidades nos territórios. A importância dessas estruturas no desenvolvimento do trabalho foi essencial para a constituição de espaços coletivos tanto de discussão, troca e 
integração e, principalmente, no próprio envolvimento dos atores no apoio de ações voltadas à promoção dos direitos das crianças e adolescentes.

Nesse formato de articulação, foram inseridas equipes interdisciplinares (184 técnicos das áreas de Psicologia, Serviço Social, Educação Física, Artes e Ciências Sociais) e estagiários distribuídos nos 34 núcleos do Programa para realizarem o diagnóstico local, a articulação da rede e as ações de execução direta com as crianças, adolescentes e suas famílias.

O trabalho das equipes teve por premissas: a) o funcionamento em rede, com adoção de estratégias que potencializassem os projetos, programas e serviços já existentes, agregando a eles as novas ações e ofertas e, com isso, garantindo um conjunto de intervenções articuladas; b) o aproveitamento dos recursos públicos e comunitários disponíveis em cada localidade, buscando a melhoria permanente dos espaços e equipamentos sociais, assim como sua utilização plena; e c) o desenvolvimento das ações em colaboração com os atores sociais envolvidos, entendendo-os como protagonistas do programa e dos resultados por ele produzidos.

\section{A trajetória de implantação do programa}

Após a aprovação no CEDCA-PR, em dezembro de 2007, a equipe da Coordenação Estadual do Programa (atribuída à SECJ) iniciou as conversações com os municípios selecionados para apresentar a proposta do Programa Atitude e apoiar a articulação necessária para o desenvolvimento dos Planos de Ação Municipais a serem submetidos à análise e conveniamento, de modo que refletissem as necessidades locais, respeitando as linhas de financiamento estabelecidas pelos eixos de ação.

Este processo prolongou-se pelo primeiro semestre de 2008. Nesse período, foram realizadas diversas reuniões com os gestores municipais, conselhos de direitos, integrantes da rede municipal de proteção à criança e ao adolescente, instituições e representantes das comunidades.

Tais articulações resultaram na formação dos embriões dos Comitês Gestores Municipais do Programa Atitude, que, com o apoio da Coordenação Estadual, tiveram por atribuições: selecionar os territórios que receberiam os núcleos do Programa utilizando-se dos mesmos indicadores adotados para a seleção dos municípios (concentração de fatores 
de risco e escassez de equipamentos e recursos para seu enfrentamento); planejar as ações a serem desenvolvidas (obras, cursos profissionalizantes, oficinas, fortalecimento dos serviços e programas já existentes) e apresentar os planos de aplicação dos recursos a serem recebidos; e estabelecer as parcerias necessárias para garantir a intersetoralidade e a articulação da rede.

Durante esse processo, os municípios adotaram ritmos diferentes de trabalho, envolvendo-se mais ou menos com o planejamento das ações do Programa, postura observada também no segundo semestre de 2008, quando a principal responsabilidade foi a de divulgar o Programa Atitude nas comunidades, sensibilizando e preparando as redes locais, assim como estabelecendo as sedes dos núcleos nos territórios com as devidas condições operacionais de trabalho.

Há que se observar que as diferenças no engajamento da preparação municipal transcorreram com maior ou menor intensidade quanto mais se aproximavam as eleições para prefeitos e vereadores municipais naquele ano, sendo que até dezembro de 2008 , o saldo positivo para o desenvolvimento das metas estabelecidas estava em maior medida correlacionado com os municípios em que não houve ruptura do comando executivo.

De toda sorte, os dez municípios apresentaram planos de ação/aplicação viáveis até o final daquele ano ao CEDCA, sendo aprovado-ajustados para cumprirem os requisitos formais do conveniamento necessário ao repasse financeiro.

A implantação do Programa e o início das ações de execução direta nas comunidades dependeram ainda do desenvolvimento de ações de âmbito estadual. A principal delas ainda nessa fase de implantação envolveu a solução para a lotação das equipes interprofissionais nos núcleos.

A ideia inicial foi o estabelecimento de parcerias com as principais Instituições de Ensino Superior do Estado juntamente com a Secretaria de Ciência e Tecnologia para o desenvolvimento de uma proposta de "Residência Técnica", cujo escopo seria o de integrar a atuação prática nas comunidades do Programa Atitude com os conteúdos e discussões relacionadas à Política de Garantia de Direitos da Criança e do Adolescente. As tratativas iniciadas resultaram em um formato de curso no modelo de Residência Técnica, de formação teórica e prática e de matriz interdisciplinar com vistas à atuação junto a crianças, adolescentes e famílias em comunidades com altos índices de violência. 
Todavia, os obstáculos da legislação trabalhista que se impuseram para a implementação da Residência Técnica não puderam ser ultrapassados do ponto de vista jurídico e administrativo, vez que a legislação federal e estadual não garantia as bases sólidas para a execução de tal proposta. Para honrar com a responsabilidade pactuada pela presença de equipe qualificada nos núcleos, a SECJ procedeu ao processo seletivo para a contratação temporária por dois anos dos profissionais do Programa. Com essa estratégia, o curso previsto para Residência Técnica foi adaptado para um Curso de Especialização lato sensu e dimensionado para a equipe contratada e para os demais integrantes da rede local de proteção à criança e ao adolescente.

Com a seleção e contratação das equipes, seguiu-se a capacitação inicial das equipes já no início de 2009. Logo após, as equipes foram divididas nos núcleos e iniciaram um diagnóstico territorial enquanto os municípios, que já haviam recebido a primeira parcela dos recursos financeiros do convênio, formalizaram a composição de seus Comitês Gestores Municipais e iniciavam a compra de equipamentos e materiais para o início das atividades do Programa.

O diagnóstico realizado nos territórios pelas equipes teve por objetivos analisar os dados da condição socioeconômica de cada região, realizar o reconhecimento territorial da área de abrangência do núcleo, identificar e negociar espaços públicos para o desenvolvimento das atividades e buscar dados referentes aos casos de violação de direitos contra crianças e adolescentes para conhecer as maiores incidências dos casos notificados.

Durante esse processo, as equipes ainda trabalharam pela divulgação do Programa, aproximação com as crianças, jovem e famílias das comunidades, buscaram se articular com os serviços existentes na comunidade, integrando-se aos fluxos de atendimento e disponibilizando-se para o apoio das ações voltadas ao público infantojuvenil.

Nessa fase da implantação do Programa, com os núcleos providos de profissionais e a proposta metodológica sendo iniciada, já era possível avaliar que os núcleos se apropriavam de suas responsabilidades e atribuições, ao mesmo tempo em que eram integrados às rotinas e dinâmicas comunitárias. Enquanto se verificavam sinais positivos dos vínculos que se estabeleciam com a comunidade e da articulação com a rede, foi ficando cada vez mais evidentes a precariedade das estruturas das sedes dos núcleos, a escassez de materiais e espaços para o desenvolvimento das atividades. Essas faltas 
deveram-se ao tempo que os municípios levaram para abrir os orçamentos municipais e executar as compras necessárias.

O prejuízo para o início das atividades do Programa era visível, assim como a criatividade das equipes em aproveitar recursos mínimos, buscar parceiros e criar soluções para o desenvolvimento do trabalho a partir dos recursos da própria comunidade. Algumas compras emergenciais de materiais foram realizadas pela própria SECJ para fornecer condições mínimas de atuação.

Apesar das condições relatadas, a fase de implantação dos núcleos concluía-se, e, com os dados dos diagnósticos locais sistematizados, cada equipe desenvolveu um planejamento pormenorizado das ações a serem desenvolvidas por eixo do Programa.

Vale registrar o início dos atendimentos com o início dos cadastros do público. A entrada no programa se deu por "demanda espontânea", além de encaminhamentos e busca ativa. Não havia restrições ou condicionalidades para a entrada no programa, a não ser a faixa etária - 07 a 18 anos. A partir do cadastramento, eram realizados estudos de caso (com visitas domiciliares), e, de acordo com a situação levantada, a equipe planejava um processo de intervenção que alcançava a família e integrava a criança/adolescente e núcleo familiar às políticas e serviços necessários, bem como às atividades desenvolvidas pelo Programa Atitude naquele território.

Na medida do possível, os integrantes do Programa eram incluídos nas atividades, cursos e oficinas de acordo com o interesse manifestado. Para aqueles que estavam fora da escola, havia um trabalho de sensibilização e motivação também articulado com o estabelecimento escolar.

A participação dos jovens bolsistas-atitude iniciou-se timidamente, expandindo-se com a estruturação dos fluxos administrativos para o pagamento do auxílio mensal de $\mathrm{R} \$$ 100,00 por mês pela SECJ. Esses jovens já vinculados ao Programa assumiam maiores responsabilidades ao se caracterizarem como "agentes de cidadania" em sua comunidade, desenvolvendo atividades em prol das crianças, demais adolescentes, jovens e famílias.

\section{Os desafios encontrados}

Gestão Compartilhada 
A opção do Programa Atitude por um formato de gestão compartilhada entre Estado e municípios fundamentou-se na tentativa de integração da rede de proteção às crianças e jovens.

Há que se considerar, entretanto, os desafios de um modelo que leva em conta a necessidade de articulação entre todos os atores que interagem no âmbito local e estadual, como também a interferência de diversos fatores que influenciam essa relação, como, por exemplo, a capacidade de gestão, fatores políticos partidários, aspectos culturais e históricos da construção das redes de proteção.

O desenvolvimento do Programa Atitude foi influenciado pela forma como a gestão compartilhada se deu em cada município. É inequívoco que a aproximação e divisão de responsabilidades tiveram impactos positivos para ambos os lados, todavia, também puderam ser encontradas resistências, dificuldades na integração entre as equipes dos núcleos contratadas pelo Estado e a rede municipal, descompasso nos objetivos e fluxos do trabalho, além de desencontros nas agendas de execução.

Tais aspectos merecem ser analisado frente a alguns prejuízos provocados para a execução direta do Programa, principalmente no alcance das metas de atendimento do público pela estrutura física e material precarizados.

Todavia, resta compreender a importância de se insistir na articulação e integração das esferas de governo, vez que no Programa Atitude ela concentrou esforços para o enfrentamento das violações de direitos contra a criança e o adolescente. Em suma, a experiência realizada foi fundamental para a constituição de redes de proteção, ao passo que evidenciou que as bases para a funcionalidade de uma gestão compartilhada requerem maior aprofundamento das relações institucionais, pactuação das condicionalidades conveniadas em maior detalhamento, além de um trabalho qualificado e intensivo no amadurecimento das relações nos Comitês Gestores Municipais.

Temporalidade/descontinuidade

O Programa teve o prazo de atuação das equipes nos núcleos preestabelecido (dois anos), sendo responsabilidade municipal dar prosseguimento às ações por meio de novas equipes ou pela absorção da demanda pela rede de serviços. 
A este respeito, a questão que pôde ser identificada ao longo do desenvolvimento do Programa foi a de que os laços estabelecidos com a comunidade foram, em grande medida, a ponte para a solução dos problemas individuais e coletivos. Nesse sentido, muitas expectativas foram levantadas, sendo que a previsibilidade dos desdobramentos futuros era restrita.

Outro aspecto que provocou descontinuidade na execução do Programa foi a intercorrência de eleições para comando executivo municipal e estadual. Os impactos decorrentes para um programa inovador e baseado em articulações governamentais e institucionais devem ser considerados como o grande desafio de se perseguir o status de política pública para programas e ações voltadas à política da criança e adolescente.

Os pontos levantados remetem à dificuldade de se garantir uma linha coerente no conjunto de ações desenvolvidas após o Programa Atitude. Os resultados alcançados, aqueles prévia e claramente estipulados ou não, em sua maioria, podem ser caracterizados como resultados "em processo", ou seja, que ainda requeriam investimento e a presença de uma equipe específica ou uma articulação entre a rede de serviços altamente eficiente para contingenciar a demanda levantada.

Transversalidades das Políticas

O Programa Atitude tomou por premissa de atuação a necessidade de se considerar a transversalidade das políticas que constituem a Política de Atendimento à Criança e ao Adolescente.

As violações de direitos identificadas pelo Programa relacionavam-se às diferentes políticas de saúde, educação, assistência social, segurança pública, habitação etc. A intervenção que se procedia, para além do atendimento direto, era a inclusão do público identificado e de suas famílias em variados serviços e programas.

O reconhecimento das atribuições e dos limites das diferentes políticas públicas, além da integração delas em uma rede de proteção à criança e ao adolescente foi um desafio para o Programa, principalmente no que se referiu às linguagens e funcionamento dos diferentes sistemas. Foi necessário concentrar esforços em estabelecer objetivos e fluxos comuns, compreender e respeitar os regramentos de cada serviço, além de sensibilizar para a prioridade absoluta do atendimento de crianças e adolescentes. 


\section{Os aprendizados}

O Programa Atitude foi uma experiência fundamental para o avanço da Política de Proteção aos Direitos de Crianças e Adolescentes. Pode ser caracterizado como um catalizador dos esforços das políticas estaduais e municipais concentradas em prol da potencialização dos fatores de proteção aos riscos que crianças e adolescentes estão expostos em territórios com altos índices de violência.

Os aprendizados vividos durante essa jornada devem ser registrados e publicizados para se garantir a devida crítica aos aspectos a serem aprimorados, assim como para se evidenciar os muitos resultados positivos que podem ser buscados e expandidos em outros territórios a partir da metodologia utilizada.

Sem dúvida, o Curso de Especialização lato sensu realizado pelas Universidades Estaduais ao longo do desenvolvimento do Programa tem um papel fundamental nessa sistematização, no aprofundamento entre a teoria e prática e na sinalização dos próximos passos a serem trilhados.

Pela observação da equipe de Coordenação Estadual do Programa Atitude, merecem destaque os seguintes pontos:

- os dados quantitativos de atendimento direto que ultrapassaram 30.000 crianças e adolescentes em atividades, cursos, oficinas e grupos com impacto positivo na vida dos atendidos, proporcionando experiências significativas para suas histórias de vida, às quais possivelmente não teriam acesso sem a intervenção governamental;

- a gradual mudança de percepção dos atores municipais, de acordo com a qual a exclusiva responsabilidade pela redução da violência praticada por jovens deixa de ser primariamente da polícia, paulatinamente reconhecendo a necessidade de mobilização de diferentes políticas estatais, comunidades, serviços, programas, profissionais e parcerias em vários níveis;

- a assinalada pluralidade e complexidade do fenômeno das violências praticadas contra crianças e adolescentes, tornando evidente a multidimensionalidade das ações de intervenção em detrimento das respostas lineares, isoladas, monofocais e somente paliativas; 
- a mobilização dos Gestores Municipais para a implantação de serviços de atendimento especializados, tais como CAPS e Centros de Proteção;

- a sensibilização de programas e serviços destinados às crianças, jovens e suas famílias para o devido acolhimento desse público e a criação de fluxos de atendimento integrados;

- a participação e o engajamento dos adolescentes e jovens na solução de problemas coletivos com experiências exitosas desse público no planejamento das ações do Programa, na reflexão sobre alternativas para o enfrentamento às violências e na intervenção comunitária;

- a promoção de discussões e debates nas instâncias do poder público sobre os fatores de vulnerabilidade e de violação dos direitos humanos fundamentais de crianças e adolescentes presentes nas situações de violência identificadas pelo Programa Atitude;

- a apropriação dos atores municipais em relação à importância da institucionalização, aperfeiçoamento e monitoramento das redes de proteção.

\section{Considerações Finais}

A temporalidade de programas e projetos sociais deve estar condicionada aos objetivos a que se propõe. Quando a intervenção é no âmbito preventivo, a duração do programa tem uma extensão maior, pois atua especificamente nas causas. Isso significa que é preciso primeiro conhecer a realidade social em que o projeto/programa se dará, considerando o seu contexto, a população e os atores sociais que dele farão parte. Uma realidade em que as situações de vulnerabilidade social, cultural e política estão presentes no cotidiano da população, o foco da ação é a transformação dessas condições de vulnerabilidades, por meio de uma atuação compartilhada em um sistema de rede.

Quando se trata de rede, por um lado, é importante lembrar que as diferentes instituições e/ou órgãos, programas e/ou projetos que a integram, necessitam construir um olhar que tomem a realidade como seu objeto de intervenção, o que exigirá maior compromisso de profissionais, em equipe interdisciplinar, empenhados em desenvolver ações que fomentem a autonomia, ampliem os espaços de valorização pessoal e reconhecimento social de modo que os protagonistas alcancem a plena cidadania. Por outro lado, a interrupção de programas e projetos sociais, em sua maioria, ocorre por um 
equívoco já bastante difundido nos órgãos públicos que, ao invés de desenvolver estratégias de intervenção como políticas de Estado, o fazem enquanto políticas de governo. A população que seria beneficiada com esses programas/projetos torna-se mais vulnerável e sente-se mais uma vez fragilizada pela miopia dos governantes.

Para finalizar, é importante lembrar que as adversidades, problemas e vulnerabilidades não podem ser combatidos em curto prazo, visto que a transformação deste contexto é complexa, multifacetada e exige compromisso político e responsabilidade social de todos que nela vivem e atuam.

\section{Referências}

CONSELHO ESTADUAL DOS DIREITOS DA CRIANÇA E DO ADOLESCENTE - CEDCA-PR. Deliberação 19/2007. Disponível em:

http://www.cedca.pr.gov.br/arquivos/File/Reunioes2008/ProgramaAtitudePublicacao.pd f. Acesso em: 20 Dez. 2012.

INSTITUTO BRASILEIRO DE GEOGRAFIA E ESTATÍSTICA - IBGE. Pesquisa nacional por amostra de domicilios-PNAD/2004 e 2006. Disponível em: <http: //www.ibge.org.br>. Acesso em: 20 Set. 2007.

INSTITUTO PARANAENSE DE DESENVOLVIMENTO ECONÔMICO E SOCIAL - IPARDES. OS Vários Paranás: estudos socioeconômico-institucionais como subsídio aos Planos de Desenvolvimento Regional. Curitiba, Ipardes, 2005.

MINISTÉRIO DA SAÙDE. DATASUS - Departamento de Informação e Informática do Sistema Único de Saúde. Disponível em: <http://www.datasus.gov.br>. Acesso em: 07 Out. 2007.

SECRETARIA DE ESTADO DA CRIANÇA E DA JUVENTUDE - SECJ. Relatórios Estatísticos do Grupo de Planejamento. Documento não publicado, 2006.

SECRETARIA DE ESTADO DA CRIANÇA E DA JUVENTUDE - SECJ. Sistema de Informação para a Infância e a Adolescência-SIPIA, Relatórios Estatísticos do Grupo de Planejamento. Documento não publicado, 2007.

SECRETARIA DE ESTADO DE SEGURANÇA PÚBLICA - SESP. Departamento: Grupo de Apoio e Planejamento. Estatísticas sobre ocorrências policiais. Documento não publicado, 2006.

SECRETARIA DO TESOURO NACIONAL - STN. Finanças Brasil (FINBRA) - Estados e municípios. Disponível em: https://www.tesouro.fazenda.gov.br/pt/component/content/article/48-prefeiturasgovernos-estaduais/417-situacao-fiscal-do-seu-municipio. Acesso em: 25 Set. 2007. 
Recebido em: 20/10/2012

Aprovado em: 15/12/2012 